\title{
The Future Fisheries: Constraints and Possibilities Sustainability - Ecological Impact from Fisheries, the Political Environment and How This May Affect the Future of Capture Fisheries
}

\author{
Hans Lassen \\ Danish Institute for Fisheries Research, Charlottenlund Slot \\ DK-2920 Charlottenlund, Denmark
}

\begin{abstract}
Fisheries, and in particular those in the North Atlantic, have attracted increased public attention in recent years. This has resulted in a change of the political climate in which fisheries shall operate in the future. In this paper, an attempt is made to identify some of the future constraints in marine fisheries. This is done on the basic assumption that future fisheries will exploit the marine resources at much lower exploitation levels than is experienced today. The analysis focuses on the fisheries themselves while the impact from society is seen as imposed constraints, e.g. the precautionary approach will be implemented to set catch limits. Market forces (costs and demands) are not discussed but obviously these forces will be very important in a full understanding of the future fisheries.

The fisheries are analysed in four subsystems: biology of the resources and ecosystem, the communities, the economy and the technology. The decision structure in fisheries are analysed in five subsections: defining constraints, defining objectives, acquisition of information, allocation of resources (fleet and labour) and finally control and enforcement.
\end{abstract}

Keywords: North Atlantic, management, biology, technology.

\section{Introduction}

Fisheries, and in particular those in the North Atlantic, have attracted increased public attention in recent years. This has resulted in a change of the political climate in which fisheries shall operate in the future. The most important political declarations in this context are:

- United Nations Conference 1992 in Rio de Janeiro, Brazil, containing Principle 15 on the Precautionary Approach (United Nations, 1992)

- Food and Agricultural Organization of the United Nations on Code of Conduct for Responsible Fisheries (FAO, 1995a)

- United Nations Conference on Straddling fish stocks and highly migratory fish stocks 1992-95 (United Nations, 1995)

There seems to be the political will to implement these intentions. If implemented, this means that for many North Atlantic fisheries, including the more important ones, the fishing mortality should be approximately halved. Scientific and political projects have been launched that aim to achieve this end (see e.g. Serchuk et al., MS 1997; ICES, MS 1997).

Fisheries management deals with fleets, fisheries and fishermen, and the traditional management model with a preoccupation on conservation of fish stocks neglects the management of fisheries, e.g. changes in fleet fishing strategies as a reaction to a management measure are not considered in details. The primary effects of fisheries management are on the social and economic subsystems and as such requires socioeconomic solutions. There are some encouraging signs that this is being widely recognized in management agencies and various approaches are being experimented with in the North Atlantic. 
This paper presents a discussion of the constraints within which fisheries shall operate in the future. While much of the discussion leading up to the political declaration concentrate on the biological limitations in sustainable exploitation of the marine fish resources, the point of view taken in this paper is broader. The analysis emphasizes that fisheries involve several subsystems, and these subsystems are influenced by the society in which fisheries are embedded. The paper briefly discusses the constraints on fisheries presented by the biological as well as other subsystems (e.g. technology, social structures and economics in the sector) influenced by fisheries.

It is the thesis of this paper that the political, social and economic restrictions, rather than the biological constraints, will determine the controversies in future fisheries. The paper attempts to identify these constraints.

The analysis is from the point of view of government. This is because it is taken almost axiomatically that the overall constraints imposed on future fisheries will be based on government decisions. The degree to which government involvement is necessary is discussed under "co-management". This is, in this context, particularly relevant when allocating fishing possibilities and fleet allocation between fish resources. To allow government to make informed decision, there must be a system available which monitors the status of the fisheries and provide projections (within the socio-economic and biological subsystems of the fisheries) based on politically defined scenarios.

\section{The North Atlantic Fisheries}

The fisheries in the North Atlantic yield 10-15 million tons of fish annually (Fig. 1), or 10-15\% of the world total marine catch of approximately 95 million tons (FAO, 1997).

The most important species are the groundfish (demersal) species Atlantic cod, haddock and saithe (called pollock in the Northwest Atlantic) together with the pelagic species Atlantic herring, Atlantic mackerel and capelin. These species account for about $50 \%$ of the catch tonnage.

The most important participants in the North Atlantic fisheries are the member states of the European Union (EU) which harvest about 35\% of the total yield, Norway (about 15\%), and Iceland, USA and Canada (about 10\% each). Other important nations are the former members of the Soviet Union and the Faroe Islands.

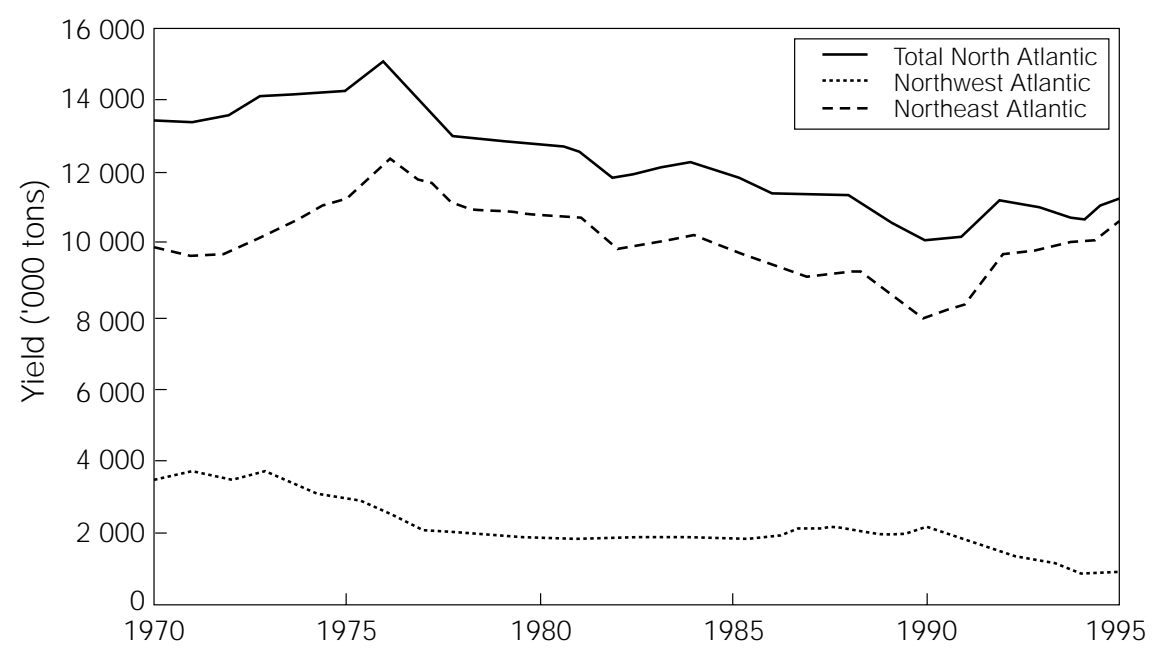

Fig. 1. Total yield ('000 tons) of marine fish from the North Atlantic, 1970-95. Based on FAO fishery statistics (of species group 3). 
The management of the fisheries in the North Atlantic has been increasing in many details since 1970, partly in response to the breakdown of the several fish stocks in the late-1960s and early-1970s, e.g. Atlanto-Scandinavian and the North Sea herring stocks. Another cause was the drop in yield in the period 1975-80. Management in the North Atlantic faces a complex fishing pattern. Many stocks are shared between several countries, e.g. nearly all stocks in the North Sea. At present the fisheries in nearly all important fish stocks are regulated. The most commonly used regulatory measure is a quota on the landings supplemented by a series of technical measures, e.g. minimum mesh sizes in the codends.

Anon. (1996), Lassen and Halliday (1997), Serchuk et al. (1996) have investigated the development in the fish assemblages in the North Atlantic. It has been found that the fishing mortalities for many stocks are even well above levels defined on a sustainable basis. This picture is universal FAO (1994 and 1995b). For the Northeast Atlantic, this is not a new situation: for many fish stocks the level of fishing was considered adequate or too high when the International Council for the Exploration of the Sea (ICES) Advisory Committee for Fishery Management (ACFM) was established in 1978, Anon. (1979).

There are economic problems in the fisheries, in spite of the fact that the fishing industry worldwide and particularly in the North Atlantic have been subsidized (FAO, 1994 and 1995b). The collapse of the Faroese fishing industry around 1990 (Mørkøre, 1991), the collapse of the cod stock on the Grand Bank and the consequences to the Newfoundland fishing industries and the Breton crisis (Delbos and Prémel, 1996) may serve as examples.

\section{Elements of the Fisheries System}

The fisheries industry can be described as closed systems or can be seen as part of the society. Such a system can be illustrated graphically (Fig. 2), where the markets and the society impose restrictions and supply possibilities for the fisheries products. Thus, the fisheries are embedded in markets for fish and fish products. Fisheries and markets are themselves part of the society and as such are influenced both by the development on the fish markets and also by the changes elsewhere in the society.

Within this closed system, the fisheries themselves are complex systems. They can be broken down into four subsystems, which can be broadly descried as biology, technology, economy and communities. With each of these subsystems, there are constraints that become evident. Some of the main ones would be as follows (Fig. 3). These four subsystems are interlinked and restrictions within any of the subsystems will have consequences in other subsystems.

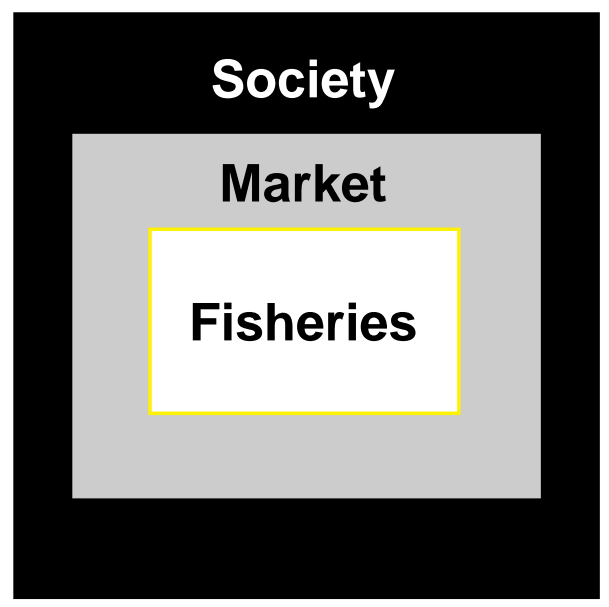

Fig. 2. Illustration of fisheries as a closed system influenced by the markets and society. 


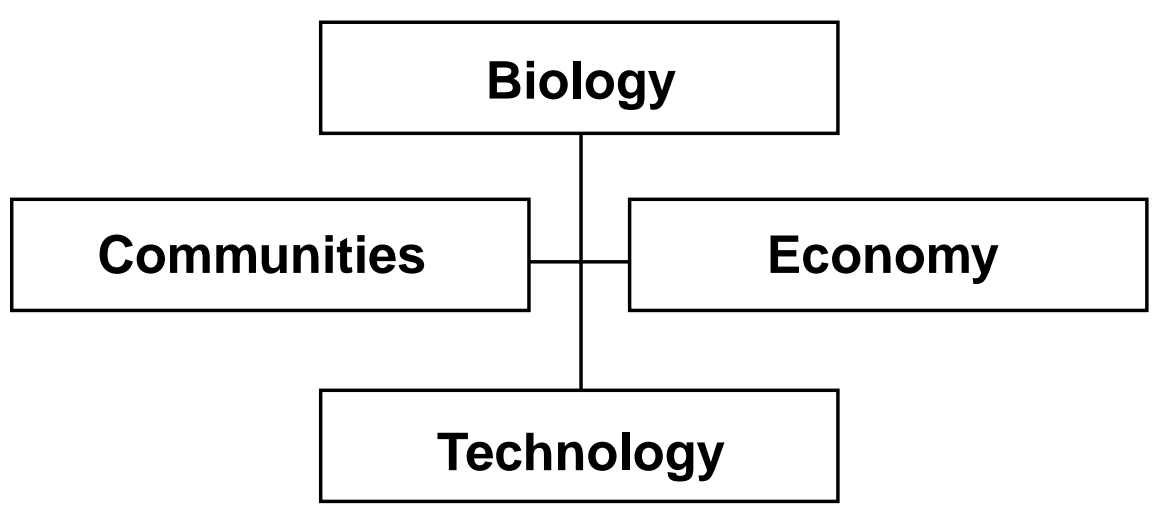

Within the biology subsystem the exploitation on the stock must be within limits. This is needed to allow reproduction in the stocks. However, the requirement for sustainable exploitation is a stronger requirement, in the event that it is not accepted that reproduction is affected by exploitation.

A confounding difficulty is technology changes as in all other sectors of the society. These technological changes often make projection of fleet behaviour and efficiency of the fleet difficult to evaluate based on historical time series.

The subsequent analysis of the constraints in future fisheries is broken down in the following five steps (modified from Christy, 1996):

- Setting constraints (biological, social and political)

- Determine objectives (biological, economical, social and political)

- Acquire information

- Allocate capital and labour

- Ensure compliance with regulations

This model seems to imply a rather tightly controlled fishing sector, almost a planned economy sector. This reflects the fundamental conflict between economic optimum fishing as perceived by the individual fisher, and optimum fishing from the society's points of view. As this conflict is in the economic subsystem of fisheries but with strong implication on the biological subsystem, the proposals for solutions discussed are in the economic and in the social structure (communities) subsystem rather than in the biological.

\section{The Constraints}

Fisheries are constrained by the processes in each subsystem, Fig. 3 and Table 1. Some of these constraints are general biological or economic constraints, others relate to the social structure of the fishing sector and others again are defined politically. These latter constraints are often specific to the fishery. Examples of constraints and their interdependence are:

- Biological subsystem - Stock productivity limitations depends on the exploitation policy defined either externally in the system or in the fisheries economic subsystem.

- Economic subsystem - Available capital (vessels and other capital goods) is limited. Economic feasibility depends on the available technology and investments depend on the expected fishing possibilities. Exploitation must be below levels where the stock becomes (commercially) extinct.

- Social structures - The type of fishery possible is related to the fishing communities in the region. If there is a surplus of fishing possibilities, there may be distant water fleets operating in the fishery. 
The social structure depends on the economy of the fisheries but also on the technology available, e.g. the maximum duration the vessels can operate.

- Technological subsystem - Technical interactions between catch of the different species depends both on the technology (selective vs unselective gears) and on how fish are mixed in the sea (biological subsystem). The available technology may leave certain species uneconomical to exploit, e.g. widely dispersed small pelagics like myctophids.

TABLE. 1. Proposed strategies for defining constraints, setting objectives, optimal allocation of fishing possibilities and capital investment and control and enforcement.

\begin{tabular}{|c|c|c|c|}
\hline Subsystem & $\begin{array}{l}\text { Defining Constraints } \\
\text { and Objectives }\end{array}$ & Allocate Fishing Possibilities & Control and Enforcement \\
\hline Biology & $\begin{array}{l}\text { Analysis of stock status } \\
-\quad \text { Catches (TAC) }\end{array}$ & $\begin{array}{l}\text { - Quotas by stock } \\
\text { - Effort control, }\end{array}$ & $\begin{array}{l}\text { - Landing control } \\
\text { Satellite surveillance a.o. }\end{array}$ \\
\hline Communities & $\begin{array}{l}\text { - Political compromise } \\
\text { between interested } \\
\text { parties }\end{array}$ & $\begin{array}{l}\text { - Co-management for } \\
\text { allocation of fishing } \\
\text { rights }\end{array}$ & - Social repercussions \\
\hline Economy & - Market for fishing rights & $\begin{array}{l}\text { - Plan economy through } \\
\text { Government inter- } \\
\text { ventions } \\
\text { - Market for fishing } \\
\text { rights }\end{array}$ & $\begin{aligned} & \text { - } \text { Market control } \\
& \text { - Effort control Satellite } \\
& \text { surveillance a.o. }\end{aligned}$ \\
\hline
\end{tabular}

Future fisheries shall be constrained and exploitation kept within sustainable limits. Sustainability has three elements:

- Biological effects on target stocks and the remainder is part of the ecosystem

- Economical viability of fishing activities

- Social viability of communities

The constraints have in many instances been defined as limitations given by the subsystem. This has been very clear for the biological subsystem, where the attitudes largely have been to allow status quo fishing as long as there were no signs of recruitment failure. The basic attitude in the "precautionary approach" is to more actively ascertain that exploitation is kept within certain limits, such limits being defined as to avoid recruitment failure at least recruitment failures, caused by too low Spawning Stock Biomass. Strictly speaking this is not the biological constraint but the limit is below the biological constraint (where the stock fails to reproduce) and the level is politically defined.

The biological sustainability concept as used in the fisheries discussions includes three issues:

- Fisheries impact on the stocks targeted directly

- Fisheries impact on other non-commercial fish stocks

- Fisheries impact on other parts of the ecosystem

The constraints in the biological subsystem have been subject to detailed analysis in recent years, and a substantial part of the FAO Code of Conduct of Responsible Fishing (FAO, 1995a) relates to these constraints. The biological sustainability of both commercial and non-commercial fish stocks is usually related to the productivity of the stock and is measured by the actual exploitation level relative to appropriate biological reference points. An alternative approach is to observe the Spawning Stock Biomass and relate that quantity to some reference point. For a full discussion, see Caddy and Mahon (1995), Serchuk et al. (MS 1997) and ICES (MS 1997). However, fisheries impact other parts of the ecosystem not only 
the marine environment, e.g. the impact includes energy consumption and the related $\mathrm{CO}_{2}$ production.

Future fisheries shall operate with significantly lower exploitation levels than we have grown accustomed to. Once the fisheries are within a constraint and remains there without too much control and enforcement effort, then such constraints are not perceived as severe restrictions in the fisheries and other constraints become more in focus. As indicated above there are numerous other limitations to fisheries within the fisheries themselves, but also imposed upon them from outside, e.g. the weather conditions.

Future fisheries in the North Atlantic will probably experience a drastic structural change to reduce overall exploitation levels and to reduce the fisheries impact on the ecosystem through improved technology. This will include fewer fishing vessels, fewer fishermen, more selective gears, and trawls with lighter bottom contact and reduction in energy consumption.

The need to dampen the social problems in fisheries communities requires a better balance between the fleet capacity and the fishing possibilities. Once such a better balance exists, the biological and social subsystems will possibly become of less concern than they are at present and other constraints in the social structures and economic subsystems will dominate the development in fisheries. Examples of such constraints are the availability of highly skilled fishers and technological limitations in selective fishing.

\section{Setting objectives}

The individual fisher and the fish producer will have their own objectives. These are not discussed here. It is the government objectives which are of interest in this discussion, as these objectives will be reflected in the regulations imposed on fisheries. Likewise the government objective will define the legal basis for enforcement and control.

Within the constraints, fisheries shall achieve certain objectives. These are often in the scientific literature formulated as one of several possibilities:

- Optimize the resource rent and economic efficiency

- Optimize employment

- Optimize yield

The resulting fishing mortality is derived as the target for the management measure. There are two fundamental different approaches to defining these objectives:

- Establish a detailed controlled fishery (planned economic solution)

- Allow free competition between fishermen, i.e. optimize the individual fisher's return (economic or otherwise)

The latter solution, see Hannesson (1993), is known for many stocks to lead to exploitation beyond sustainable limits and government needs to confine the competition for the fish to be within certain limits defined by society. Therefore society (government) plays an active role in allocating fishing possibilities if only in setting the overall limitations on the exploitation. Society therefore needs to decide explicitly what the criteria should be for setting these limits. As an example the ITQ system is often formulated as the right to a fixed share of the total TAC, see e.g. Grafton (1996).

Setting the overall limits on exploitation is in theory based on a scientific analysis of the stock status. This analysis however has to be based on objectives which are often not formulated. Therefore the advisory committees provide management options within "safe biological limits", see Serchuk and Grainger (MS 1992), and leave it to the management committees to interpret these management options within their own objectives. However management decisions can also be seen as a more chaotic decision process, where interested parties seek political compromises and where each party has a multitude of (most likely) conflicting objectives, see Lassen (1991). 
The biological objectives are explicitly formulated, e.g. maintain the spawning stock biomass above the Minimum Biological Acceptable Limit (MBAL). The economic subsystem likewise may propose a clear objective, achieve economic efficiency in the catching sector, maximize resource rent, asf. Objectives in the social sphere are often less well defined.

Future fisheries will also suffer from these undefined, and therefore untransparent, objectives in the social and partly economic sectors. This is because these objectives have direct implication on the distribution of wealth between the interested parties. The future fisheries will therefore continue to be developed and regulated on partly undefined objectives. While the detailed distribution of the fishing possibilities between fleets and vessels may be regulated through a market for fishing rights (in \% of overall TAC or in kg quota), the overall limitations and likely sharing of the overall TACs between nations will probably continue. Within the European Union it would be logical to have an open market for fishing rights. However the community problems associated with such a drastic step will need to be resolved first. An open market would allow, e.g. a Mediterranean based fishing company to buy fishing rights on Barents Sea Cod (within the EU quota). Thus, fishermen traditionally participating in those fisheries could become unemployed.

\section{Information Acquisition}

Information at the government level needed to make the fisheries work can be categorized as: 1) for project development in order to make decisions which shall achieve the stated overall objectives, and 2) for retrospective analysis to evaluate if the decisions have let to the desired goals. As the objectives relate to all four subsystems discussed above relating to Fig. 3, information on the state of each subsystem is needed as shown in Table 2.

TABLE 2. Elements in fisheries subsystems.

\begin{tabular}{|c|c|c|c|c|c|}
\hline Subsystem & Constraints & Objectives & $\begin{array}{c}\text { Acquire } \\
\text { Information }\end{array}$ & Allocate & $\begin{array}{l}\text { Control and } \\
\text { Enforcement }\end{array}$ \\
\hline Biology & $\begin{array}{l}\text { Sustainability } \\
\text {-Target stocks } \\
\text {-Non-target stocks } \\
\text {-Ecosystem }\end{array}$ & $\begin{array}{l}\text { Limit with sustainable exploitation } \\
\text {-Fishing mortalities } \\
\text {-Spawning stock biomass }\end{array}$ & $\begin{array}{l}\text {-Stock status } \\
\text { - Sustainable limits for } \\
\text {-exploitation of stocks }\end{array}$ & $\begin{array}{l}\text {-Fishing } \\
\text { possibilities by } \\
\text { stock }\end{array}$ & $\begin{array}{l}\text {-Catches, species } \\
\text { and stock } \\
\text { identification }\end{array}$ \\
\hline Communities & -Social unrest & $\begin{array}{l}\text { - Ensure viable communities } \\
\text {-Avoid depopulation } \\
\text { - Minimize changes in fisheries } \\
\text { community }\end{array}$ & $\begin{array}{l}\text { - Regional economic } \\
\text { data } \\
\text {-Population statistics }\end{array}$ & $\begin{array}{l}\text {-Fishing } \\
\text { possibilities by } \\
\text { fleet and region }\end{array}$ & \\
\hline Economy & $\begin{array}{l}\text { - Sustainable fisheries } \\
\text {-Limited capital } \\
\text { resources }\end{array}$ & -Efficiency & $\begin{array}{l}\text {-Income } \\
\text {-Costs of fishing } \\
\text {-Employment } \\
\text { - Resource rent } \\
\text { - Return to capital }\end{array}$ & $\begin{array}{l}\text {-Economical } \\
\text { allocation by } \\
\text { government decree } \\
\text { - Markets for } \\
\text { fishing rights }\end{array}$ & $\begin{array}{l}\text { - Market control } \\
\text { - Income control } \\
\text { - Effort control } \\
\text { includes satellite } \\
\text { surveillance a.o. }\end{array}$ \\
\hline Technology & $\begin{array}{l}\text { Limit } \\
\text { - Technical inter- } \\
\text { actions } \\
\text {-Access to certain } \\
\text { resources }\end{array}$ & $\begin{array}{l}\text { - Selective gears } \\
\text { - Minimum ecosystem impact } \\
\text { - Low cost and low energy fishing }\end{array}$ & -Technological options & $\begin{array}{l}\text { - Resources to R \& D } \\
\text { programs }\end{array}$ & \\
\hline
\end{tabular}

Concerning the biological subsystem, there are monitoring programs that provide estimates of the current exploitation and of current stock sizes. These monitoring programs include fisheries statistics (catch and effort), biological samples of the catches (age distributions) and surveys carried out by research vessels (abundance indices). These data form the basis for national or international level decisions on fisheries. Often the international scientific advisory systems produce annual reports of the status of the fish stocks. In the Northeast Atlantic, it is the International Council for the Exploration of the Seas (ICES) through its Advisory Committee for Fishery Management (ACFM) that provides the major part of this advice. There are other organizations which provide advice, e.g. International Council for the Conservation of Atlantic Tunas (ICCAT) which assess the tuna and swordfish stocks. In the Northwest Atlantic, 
the Northwest Atlantic Fisheries Organization (NAFO) assess fish stocks outside the EEZ areas, while within coastal areas bodies such as the Canadian and United States national assessment committees deal with other components of the fish assemblage. The amount of data available varies between stocks. Generally, it is the importance attached to a stock which has determined the amount of research done on the stock, rather than a difference between east and west.

Data on the status of the socio-economic subsystem are available at national levels, for example at the level of geographical regions, but are not aggregated internationally to the same degree as are the biological data. Previously the differences between countries, particularly in the Northeast Atlantic, made it difficult to aggregate data across nations, however, the political developments within the European Union has made this simpler. Also the existence of the EU Common Fisheries Policy, potentially allows for agreed objectives at the socio-economic level. In the eastern Atlantic, the future fisheries analysts probably will have more homogeneous socio-economic data available.

Technological developments are subsidized by governments, and there are agreed objectives to achieve better selective gears and gears causing minimal damage to the ecosystems. For these objectives, the required information on the technological options is available to the program committees, institutions, etc.

The biological scientific programs provide projections of future yields based on specified options of fishing mortalities. Equally important, but having received much less attention, is the link between management measures and the resulting fishing mortality. The management programs to date have all been based on the assumption that such links exist. Therefore, future requests from management for scientific advice will probably be much more specific in requiring these links. It is clear that the ability of the fishing fleet to adapt and circumvent regulations is formidable, and that regulations can result in quite unexpected outcomes.

Future fisheries management will need a more thorough understanding of the fisheries system. Questions needed to be considered are for example: how will the fishing fleet react to a restriction? Will they adapt, leave the fishery or circumvent the restriction? There is thus a need for an extension of the classical fisheries science to include the study of fleet reactions to restriction. Such restrictions can be imposed by management but can also be forced upon the industry by nature. Fleet reactions are determined by people - fishermen, industrial managers etc. - and proper science would therefore naturally be the starting point on how decisions are made, and how organizations react to restrictions where they are externally imposed.

The role of economic studies in the planning of future fisheries is much debated at present. For example, ICES has had several theme sessions at its annual science meetings in the 1990s. A key problem of the economic aspects is that the biological advisory system, e.g. ICES and NAFO, are build around biological units, ecosystems and stocks with little regard to the economic units. This is particularly true at national levels, e.g. Norway, EU, Canada and USA. If the biological problems with overexploitation become less of an issue in the future (because a lower fishing mortality will be achieved) and if a better balance between fleet capacity and fishing possibilities will be achieved, then the socio-economic problems will become central. Then it will be the restructuring that will be the focus, e.g. determining which fishers shall leave the trade will probably create the biggest problems. Those left will hopefully experience high catch rates, i.e. low costs per produced amount of fish, and with less fierce competition for the resources than seen at present. In this scenario there will be little need for information of the socioeconomic status of the sector.

\section{Allocation of Resources - Defining Fisheries Management}

The problem of fishery resource allocation needs to be dealt with at several levels:

1. The overall share of the available fish resources which can be taken must defined. Although this is based on input from the scientific fish stock assessments, in practice there are considerations which strictly belong to the subsequent sharing between interested parties which get entertained. 
2. Where there are several nations involved in the fishery, the overall TAC must be shared between the nations.

3. Within each nation there will be sharing of the fishing possibilities by the fisher.

The first two tasks are clearly government responsibility, while the national sharing is not necessarily so. The systems presently operating around the North Atlantic involve a substantial government input, but some countries have introduced various forms of "user rights" systems leaving the sharing to a market for fishing possibilities, see Grafton (1996) for a review of the experiences with these Individual Transferable Quotas (ITQ).

The overall setting of a TAC or a limit on fishing by an equivalent regulatory mechanism is required since the open access or "free fishing" (see Christy, 1996) for a recent discussion of the issue), often leads to serious overexploitation. This requires significant input from government. The sharing between nations follows in many cases, e.g. most stocks in NAFO and EU have an agreed formula and therefore are no issues in the annual setting of TACs. These formulae were derived from often painful and lengthy political debates.

There are two fundamental different attitudes to the allocation problem between fishers:

- Allow fishing within certain limits, e.g. monthly rations by vessel based on a formal or an informal license system.

- Establish user rights to shares of the national TAC and create a market for the trade of these user rights or fishing possibilities. This is the Individual Transferable Quota system (ITQs).

The first proposal with a quota regulation focuses on the biological subsystem and the need to restrict fishing exploitation on the stock but does not address issues in the other subsystems. The ITQ system addresses issues primarily in the economic subsystem a third strategy co-management (Sen and Nielsen, 1996) where the government delegates management responsibilities to the fishing sector is primarily directed to address issues at the community subsystem (Fig. 4).

The costs, not least the political costs, in the detailed fisheries management have become very high. It is obvious that a strategy with more user group management would be cheaper for government. It appears therefore that the trend in allocation will be towards systems with less government involvement on the detailed allocation level. Whether this will be through a market based system or through a community system probably depends on the characteristics of the fishery. The corporate structure of the fishery will likely be of major importance. ITQ systems are probably less suitable for small scale fisheries than for larger fisheries.

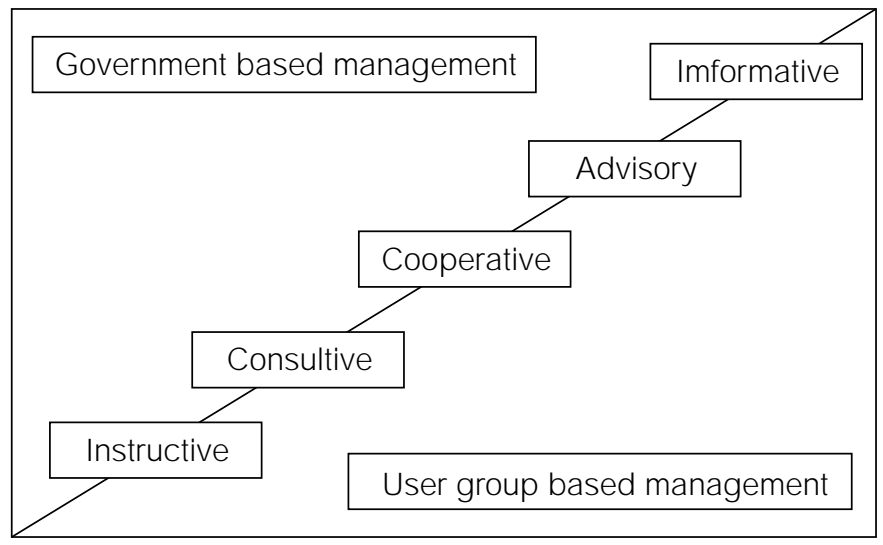

Fig. 4. Spectrum of co-management arrangements (from Sen and Nielsen, 1996). 


\section{Ensure compliance with the management plans}

Compliance with the fisheries management measures is a must to achieve the stated objectives. It is however not sufficient because the measures taken may lack understanding of the system which we try to manage. The experiences in the 1980s have shown that it is difficult or impossible to police at a sufficient level to ensure compliance. The costs are simply too high to be acceptable and government possibilities are limited by the acceptance by the society of the means to police the sector.

Compliance with fisheries regulations has been low in many fisheries - management has lost its legitimity in the fishing sector. Further, it is recognized that it is not possible to police the fisheries in sufficient detail to ensure compliance. The solution must be to achieve a higher degree of acceptance of the regulations than has been the case hitherto. Social scientists have pointed to the importance of the social structures in this context and have proposed that delegation of the responsibility on the well being of the fisheries co-management could help to achieve better compliance in the future.

For a detailed discussion of the European Union situation see Holden (1994) while Halliday and Pinhorn (1996) present a general overview and discussion for the North Atlantic fisheries.

Social science has pointed to the importance of the social structures in connection with implementation of the management. It is recognized that by the very nature of the fisheries management measures the stated objectives can only be achieved if all involved parties accept and implement the regulation.

It seems to be a result of the changed political climate around the environment and the exploitation of resources that society will take a more severe look on trespassing of fisheries regulations, Rosenberg (1998). This may help in establishing some community structure around enforcement and control. Because of the biological externalities in the fisheries an individual fisherman will get personal benefit from trespassing the regulations while if all trespass all will suffer. In order to keep everyone on track it is therefore necessary that there is a substantial amount of internal self-control among the fishermen and in the fishing sector. Considering our past experiences this depends whether the competition for the fish resources will be reduced, i.e. whether the fishing mortalities and fishing effort will be reduced. Under the present fierce competition strict external control is likely to be required well into the next century.

Technology offers an increasing number of possibilities for remote monitoring of the activities of fishing vessels, e.g. satellite tracking. These technological options are at the moment able to provide information on the fishing effort while little if any information on the catches. As these technological options offer cheaper control than catch control, e.g. by observers at sea, it is likely the future fisheries management systems will have a larger element of effort control than is laid down in the regulations of to day.

\section{The Fisheries of the Future}

1. The future fisheries will operate under more severe restrictions than they have experienced until now because of the growing political awareness of the fisheries' impact on the ecosystem and the lack of political acceptance of these effects.

These effects are grouped as:

- Reduction of the exploitation pressure.

- Technological improvements towards gears with better selectivity properties and with less impact on the ecosystem and towards fishing methods using less energy. It is quite possible that certain gears, e.g. beam trawls and drift nets, will not be allowed in the future due to their impact on, bottom fauna and marine mammals.

- Increased economic return to the fisheries due to increased catch rates, a derived effect from the reduction of the exploitation pressure. 
- Social changes from increased income and possible concentration of the fishing rights.

The restriction where the effects are probably better understood is the reduction in the exploitation pressure. This will reduce the fleets - or at least should do so if economic efficiency is desired. The number of fishermen would decline correspondingly. This is a process that has been ongoing for many years in the economies around the North Atlantic. The total yield would however not be affected and therefore the effects on the production sector and the consumer market would be fairly small. Future catches would however consist of larger fish and in some cases of fewer fish. This will affect the production sector. The costs of fishing per unit of landing would decrease as the CPUE - catch $(\mathrm{kg})$ per unit effort - would increase corresponding to the increased abundance expected under decreased exploitation levels.

Reducing the impact from fisheries on the ecosystem will in the first instances get a technological answer: more selective gears and lighter trawls, developments are underway. It is quite possible that certain gears, e.g. beam trawls and drift nets, will not be allowed in the future due to their impact on, e.g. bottom fauna and marine mammals. There are programs aimed at modifying such gears. Reduction of energy consumption is part of the general policy accepted around the North Atlantic to reduce $\mathrm{CO}_{2}$ production. The energy saving policy may be taken as far as a ban on trawl fishing over gill netting at least in some fisheries.

2. Economists have focused attention on the introduction of a market of fishing rights, see e.g. Neher $e t$ al., (1989). This has been formulated as a management tool of Individual Transferable Quotas (ITQ). This system has been introduced in several fisheries (for some experiences see Munro and Pitcher (eds.), 1996). The experiences suggest that this system leads to improved economic efficiency (Grafton, 1996) but also affects the social structures in the fisheries particularly leading to a concentration of fishing rights on a few owners ("quota kings", Pálsson and Helgason, 1996). These effects are considered by some as adverse effects. Whether this is a result of the application of ITQs as a management tool or whether this simply follows the general trend in the economies in the same period cannot be determined.

3. Future decisions on national allocation of fishing possibilities will be delegated from government organizations to the fishing industry and other interested parties - some form of co-management ITQs should be seen in that light as ownership of a proportion of a total TAC delegated to the industry or to private persons. Under such schemes government action is restricted to establishing the total TAC and controlling that the industry comply with the TAC and technical measures.

4. Analyses of fisheries management systems need a wider scope than we have seen so far. It will be necessary to better understand the interplay between the four subsystems to establish an efficient management system. It should be recognized that apart from establishing sustainable limits and measuring the status of the fish stocks relative to such limits the biology has little to offer management. Management affects people, therefore the relevant analysis/advice should be based on disciplines other than biology. Fisheries management measures are political answers to technological, economical and social questions. If there is a biological problem, i.e. threatening the productivity of the fish stock then the answer is to bring this agent (pollution, fishing, etc.) under control, e.g. restricting fishing. The appropriate measure may use biological features of the fish stock but fundamentally biology is unable to advise whether a particular measure will best achieve the objective. There is therefore a need for fisheries management science as discussed by Stephenson and Lane (1995) or at the very least a co-ordination of the research in the socio-economic fisheries field.

This change in perspective will have significant implications on the assessments - the scientific emphasis will shift from a biological study of the fish stocks and their productivity to understanding the fisheries. This understanding of the fisheries will include the classical population dynamics approach because no fish - no fisheries, but will also include studies of the economy and institutional constraints of the fisheries. 
5. The organizational model using the present organizations ICES, NAFO and ICCAT where the science is dominated by biological considerations should be reconsidered. The emphasis should be equally concentrated on fisheries and fish stocks while the present set-up largely ignores the fisheries and only provide information on the status of the fish stocks.

\section{References}

ANON. 1979. Reports of the ICES Advisory Committee on fishery management. Coop. Res. Rep., No 85.

1996. Report of a Group of Independent Experts to advice the Commission on the Fourth Generation of the Multiannual Guidance Programme, EU Commission, Directorate General XIV (Fisheries), April 1996.

CADDY, J. F., and R. MAHON. 1995. Reference points for fishery management FAO Tech. Pap., No. 347.

CHRISTY, F. T. 1996. The Death rattle of open access and the advent of property rights regimes in fisheries. Marine Resource Economics, 11: 287-304.

DELBOS, G., and G. PRÉMEL. 1996. The Breton Fishing Crisis in the 1900s: Local Society in the Throes of Enforced Change. In: Fisheries Management in Crisis, K. Crean and D. Symes (eds.). Fishing News Books, Oxford, UK.

FAO. 1994. Review of the state of the world marine fishery resources. FAO Tech. Pap., No 335.

1995a. Code of conduct on responsible fisheries. Food and Agriculture Organization of the United Nations, Rome.

1995b. Review of the state of the world fishery resources: marine fisheries. FAO Fish. Circ., No 884, 105 p.

1997. Fisheries statistics - catches and landings, Vol 80, 1995. Food and Agriculture Organization of the United Nations, Rome.

GRAFTON, R. Q. 1996. Individual transferable quotas: theory and practice. Reviews in Fish Biology and Fisheries, 6(1): 5-20.

HALLIDAY, R. G., and A. T. PINHORN. 1996. North Atlantic fishery management systems: a comparison of management methods and resource trends. J. Northw. Atl. Fish. Sci., 20: 9-135.

HANNESSON, R. 1993. Bioeconomic analysis of fisheries. Fishing News Books, Blackwell Scientific Publications Ltd., Oxford, UK.

HOLDEN, M. 1994. The common fisheries policy: origin, evaluation and future. Fishing News Books, Blackwell Science Ltd. Oxford, UK.

ICES. MS 1997. Report of the ACFM Study Group on the precautionary approach. ICES C.M. Doc., No. Assess: 7.

LASSEN, H. 1991. Biological uncertainties in fish stock management: a discussion. NAFO Sci. Coun. Studies, 16: $165-170$.

LASSEN, H., and R. HALLIDAY. 1997. Biological advice on fishery management in the North Atlantic 1970-1995. 273-282 in World Fisheries Congress (2nd: 1996: Brisbane Qld), CSIRO, Australia 1997.

MUNRO, G. R., and T. J. PITCHER. 1996. Special issue on individual transferable quotas. Reviews in Fish Biology and Fisheries, $\mathbf{6}(1)$.

MØRKØE, J. 1991. Et korporativt forvaltningsregimes sammenbrud - erfaringer fra det færøske fiskeri i nationalt farvand. In: 'Fiskerireguleringer': Nordiske Seminar og Arbejdsrapporter No. 510, Nordisk Ministerråd, Copenhagen (in Danish) (Collapse of a corporative management system - experiences from the Faroese fishery in National waters).

NEHER, P. A., R. ARNASON, and N. MOLLETT (ed.). 1989. Rights based fishing. NATO ASI Series. Series E: Applied Sci., Vol 169.

PÁLSSON, G., and A. HELGASON. 1996. Property rights and practical knowledge: the Icelandic quota system. In: Fisheries Management in Crisis, K. Crean and D. Symes (eds.). Fishing News Books. Blackwell Science Ltd., Oxford, UK.

ROSENBERG, A. A. 1998. Controlling marine fisheries 50 years from now. J. Northw. Atl. Fish. Sci., 23: $95-103$ (this volume).

SEN, S., and J. RÅKJÆR NIELSEN. 1996. Fisheries co-management: a comparative analysis. Marine Policy, 20: 405-418.

SERCHUK, F. M., and R. GRAINGER. MS 1992. Form of ACFM Advice. ICES C.M. Doc., No. Assess: 20.

SERCHUK, F. M., E. KIRKEGAARD, and N. DAAN. 1996. Status and trends of the major roundfish, flatfish, and pelagic fish stocks in the North Sea: thirty-year overview. ICES J. Mar. Sci., 53(6): 1130-1145.

SERCHUK, F., D. RIVARD, J. CASEY, and R. MAYO. MS 1997. Report of the ad hoc Working Group of the NAFO Scientific Council on the precautionary approach. NAFO SCS Doc., No. 12, Serial No. N2911, 61 p.

STEPHENSON, R. L., and D. LANE, 1995. Fisheries Management Science: a plea for a conceptual change. Can. J. Fish. Aquat. Sci.: 2051-2056.

UNITED NATIONS. 1992. United nations Conference on the Environment and Development. Earth Summit, Rio, 1992. 
1995. Agreement for the Implementation of the Provisions of the United Nations Convention on the Law of the Sea of 10 December 1982 relating to the Conservation and Management of Straddling Fish Stocks and Highly Migratory Fish Stocks, 4 Dec. 1995. UN Doc. A/Conf.164/37. 
